\title{
Effects of Resveratrol on Memory Performance, Hippocampal Functional Connectivity, and Glucose Metabolism in Healthy Older Adults
}

\author{
A. Veronica Witte, ${ }^{1,2}$ Lucia Kerti, ${ }^{1}$ Daniel S. Margulies, ${ }^{4}$ and Agnes Flöel ${ }^{1,2,3}$ \\ ${ }^{1}$ Department of Neurology, ${ }^{2}$ NeuroCure Cluster of Excellence, and ${ }^{3}$ Center for Stroke Research Berlin, Charité-Universitätsmedizin Berlin, 10117 Berlin, \\ Germany; and ${ }^{4}$ Max Planck Research Group: Neuroanatomy and Connectivity, Max Planck Institute for Human Cognitive and Brain Sciences, 04103 \\ Leipzig, Germany
}

Dietary habits such as caloric restriction or nutrients that mimic these effects may exert beneficial effects on brain aging. The plant-derived polyphenol resveratrol has been shown to increase memory performance in primates; however, interventional studies in older humans are lacking. Here, we tested whether supplementation of resveratrol would enhance memory performance in older adults and addressed potential mechanisms underlying this effect. Twenty-three healthy overweight older individuals that successfully completed 26 weeks of resveratrol intake $(200 \mathrm{mg} / \mathrm{d})$ were pairwise matched to 23 participants that received placebo (total $n=46,18$ females, $50-75$ years). Before and after the intervention/control period, subjects underwent memory tasks and neuroimaging to assess volume, microstructure, and functional connectivity (FC) of the hippocampus, a key region implicated in memory functions. In addition, anthropometry, glucose and lipid metabolism, inflammation, neurotrophic factors, and vascular parameters were assayed. We observed a significant effect of resveratrol on retention of words over 30 min compared with placebo $(p=0.038)$. In addition, resveratrol led to significant increases in hippocampal FC, decreases in glycated hemoglobin (HbAlc) and body fat, and increases in leptin compared with placebo (all $p<0.05$ ). Increases in FC between the left posterior hippocampus and the medial prefrontal cortex correlated with increases in retention scores and with decreases in $\mathrm{HbAlc}($ all $p<0.05)$. This study provides initial evidence that supplementary resveratrol improves memory performance in association with improved glucose metabolism and increased hippocampal FC in older adults. Our findings offer the basis for novel strategies to maintain brain health during aging.

Key words: Aging; CR-mimetic; HbAlc; microstructure; resting-state fMRI

\section{Introduction}

Dietary habits such as caloric restriction (CR) or specific nutrients that mimic these effects (CR mimetics) may exert beneficial effects on the aging brain (Ingram et al., 2007; Stranahan and Mattson, 2008). A promising CR-mimetic nutrient is the polyphenol resveratrol (3,5,4' -trihydroxy-trans-stilbene), which occurs naturally in the skin of red grapes, red wine, blueberries, peanuts, and Japanese knotweed (Baur and Sinclair, 2006; Baur et al., 2006; Ingram et al., 2006). In rodent models of Alzheimer's disease $(\mathrm{AD})$, resveratrol intake has been shown to prevent

Received Jan. 28, 2014; revised April 16, 2014; accepted April 22, 2014.

Author contributions: A.V.W. and A.F. designed research; A.V.W. and L.K. performed research; A.V.W. and L.K. analyzed data; A.V.W., L.K., D.S.M., and A.F. wrote the paper.

This work was supported by the Deutsche Forschungsgemeinschaft (Grants FI379-8/1, 379-10/1, 379-11/1, and DFG-Exc 257), the Else-Kröner Fresenius Stiftung (Grant 2011-119), and the Bundesministerium für Bildung und Forschung (Grants FKZ 0315673A, 01GY1144, and 01E00801). We thank Henrike M. Herrmannstädter and Angela Winkler for help with data acquisition.

The authors declare no competing financial interests.

Correspondence should be addressed to either Veronica Witte or Agnes Flöel, Universitätsmedizin Charité, CCM, Department of Neurology, Charitéplatz 1, 10117 Berlin, Germany, E-mail: veronica.witte@charite.de or agnes.floeel@charite.de.

A. V. Witte's present address: Max Planck Institute for Human Cognitive and Brain Sciences, Department of Neurology, 04103 Leipzig, Germany.

DOI:10.1523/JNEUROSCI.0385-14.2014

Copyright $\odot 2014$ the authors $\quad 0270-6474 / 14 / 347862-09 \$ 15.00 / 0$ streptozotocin-induced cognitive impairment (Sharma and Gupta, 2002) and to protect against learning impairment and hippocampal neurodegeneration (Kim et al., 2007). In addition, administration of red wine was found to preserve spatial memory and $\mathrm{A} \beta$ neuropathology (Wang et al., 2006). In a primate study, supplementary resveratrol for 18 months increased spatial memory performance compared with placebo (Dal-Pan et al., 2011).

Resveratrol may induce its neuroprotective properties by reducing mitochondrial dysfunction, oxidative damage, and chronic inflammation; by improving vascular function; and by activating longevity genes including sirtuins (for review, see Sun et al., 2011). For example, resveratrol treatment led to improved insulin sensitivity (Baur et al., 2006) and mitochondrial function (Lagouge et al., 2006) in obese rodents. In addition, diabetic or hypertensive cell and animal models have demonstrated that resveratrol reduces advanced glycation end-product-mediated oxidative DNA damage (Mizutani et al., 2000), improves endothelial function (Silan, 2008), lowers blood pressure (Miatello et al., 2005), and exerts anti-atherogenic and cholesterol-lowering properties (Do et al., 2008). In addition, resveratrol intake has been found to downregulate inflammatory cytokines in several conditions (Csiszar et al., 2009).

Whether the above-described benefits of resveratrol can be translated to humans remains to be established. Small interven- 


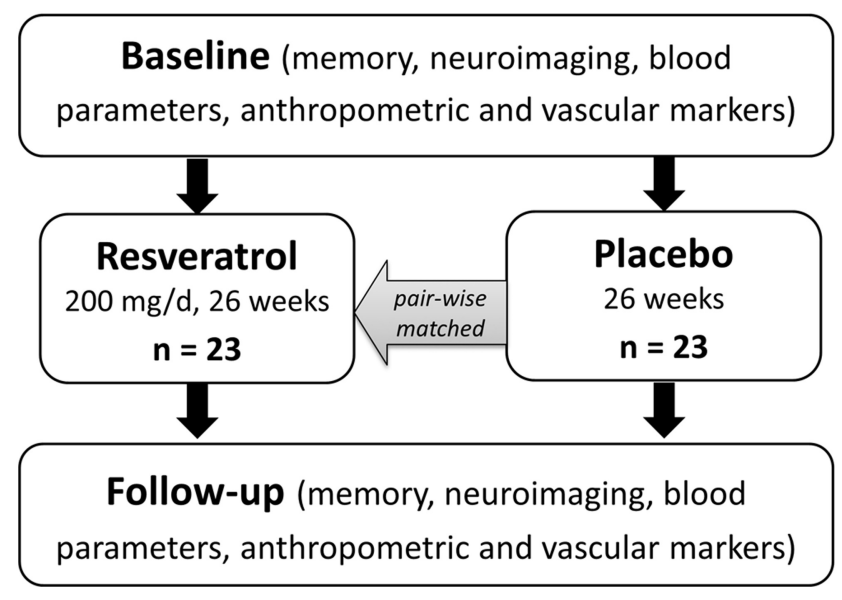

Figure 1. Flowchart of the study. Twenty-three healthy overweight older adults successfully completed 26 weeks of resveratrol intake $(200 \mathrm{mg} / \mathrm{d}$ ) and were pairwise matched to 23 control subjects receiving placebo supplementation. Before and after the intervention/control period, subjects were tested for memory performance and underwent $3 T$ MRI neuroimaging to evaluate resting-state $F C$, volume, and microstructure of the hippocampus. In addition, fasting blood samples were taken to assess markers of glucose metabolism, lipid profile, inflammatory parameters, and neurotrophic factors.

tional studies observed positive effects after 4 weeks of supplementary resveratrol intake on glucose/insulin metabolism in patients suffering from type 2 diabetes (Brasnyó et al., 2011), impaired glucose tolerance (Crandall et al., 2012), and obesity (Timmers et al., 2011). In addition, plasma levels of proinflammatory cytokines were reduced after 6 weeks of resveratrol treatment (Ghanim et al., 2010). Immediate positive effects on vascular parameters were seen in two studies focusing on endothelial function (Wong et al., 2011) and cerebral blood flow (Kennedy et al., 2010). However, interventional studies investigating potential effects of long-term resveratrol supplements on learning and memory formation are lacking and whether the abovedescribed systemic effects would be associated with benefits on the neuronal and functional level in the hippocampus of older humans remains unknown. We therefore conducted a doubleblind placebo-controlled study (for a flow chart, see Fig. 1) to assess the effects of supplementary resveratrol, given over 26 weeks in a formula with quercetin to increase its bioavailability (De Santi et al., 2000), on memory performance in a cohort of healthy older adults. In addition, volume, microstructure, and resting-state functional connectivity (FC) of the hippocampus, a key region implicated in memory functions, were explored using magnetic resonance imaging (MRI) at 3 tesla. To further address potential mechanisms, we assessed anthrophometric data, peripheral blood parameters, and vascular markers including carotid intima media thickness (CIMT).

\section{Materials and Methods}

Participants and study design. Healthy older adults (50-80 years) were recruited via advertisements in Berlin, Germany. Because the physiological response to resveratrol may be more pronounced in overweight persons (Must et al., 1999; Wild et al., 2004; Timmers et al., 2011), we opted for an overweight cohort (body mass index, BMI, of $25-30 \mathrm{~kg} / \mathrm{m}^{2}$ ). Volunteers underwent a telephone screening to clarify major exclusion criteria, including history of severe untreated medical, neurological, and psychiatric diseases; diabetes mellitus type 2; intake of antidepressants; daily consumption of $>50 \mathrm{~g}$ of alcohol, $>10$ cigarettes, or $>6$ cups of coffee; not native German speaking; and a BMI $<25 \mathrm{~kg} / \mathrm{m}^{2}$ or $>30$ $\mathrm{kg} / \mathrm{m}^{2}$. During baseline visits, subjects underwent a standardized medical interview and a neurological examination. The Mini Mental State
Examination (MMSE; Folstein et al., 1975) was used to test for cognitive impairment (exclusion if scores $<26$ points). Psychiatric comorbidity was additionally monitored using the Beck's Depression Inventory (BDI; Kuhner et al., 2007). After baseline sessions, 24 randomly chosen participants comprised the intervention group and received supplementation capsules. Subjects were told to follow a daily intake of four capsules (in total $200 \mathrm{mg}$ of resveratrol and $320 \mathrm{mg}$ of quercetin) over a period of 26 weeks. One subject failed to follow dietary instruction (i.e., self-reported misses of capsule intake $>5$ times/week), leaving 23 subjects in the resveratrol group. As control group, 23 subjects were pairwise matched to the intervention group for sex, age, and BMI (Table 1). Subjects of the control group received placebo capsules. All subjects received a 13 week supply of capsules and another 13 week supply after 3 months. They were instructed to follow a daily intake of four capsules per day, two before or at the first main meal and two before or at the second main meal, over a period of 26 weeks. Resveratrol was isolated from Japanese knotweed tree. The placebo capsules consisted of $1015 \mathrm{mg}$ of sunflower oil. Placebo capsules were indistinguishable from resveratrol capsules. All capsules were provided by Via Vitamine.

Before and after the intervention/control period, we assessed memory performance, neuroimaging, serum parameters, anthropometric data, and vascular markers (Fig. 1). Subjects and investigators were blinded to the treatment group. The study was conducted at the Department of Neurology at the Charite University Hospital of Berlin, Germany. All subjects provided written informed consent and received reimbursement for participation. The research protocol was approved by the Ethics Committee of the Charité Universitätsmedizin Berlin and was in accordance with the Declaration of Helsinki.

Compliance. Compliance was monitored by evaluation questionnaires at the end of the study and by capsule counts after 12 and 26 weeks. In addition, subjects had to fill out nutrition protocols over a period of $7 \mathrm{~d}$ at baseline, after 12 weeks, and again after 26 weeks. They were instructed not to change their dietary habits throughout the intervention.

Neuropsychological testing. Subjects were tested on memory performance with the German version of the Auditory Verbal Learning Test (AVLT; Lezak, 2004; Kerti et al., 2013) using parallel versions to avoid test-retest effects. Participants had to remember and recall a list of 15 words within five immediate recall trials, followed by a $30 \mathrm{~min}$ delayed recall and recognition trial. Memory "retention" was defined as the number of correct words recalled after the fifth trial (maximum 15 words) subtracted from those correctly recalled after the 30 min delay (maximum 15 words) multiplied by -1 to create positive relations. "Delayed recall" was defined as the number of correctly recalled words after the 30 min delay (maximum 15 words) and "recognition" was defined as the number of correctly recognized words minus false positives out of a subsequent list of 45 words read out loud that comprised 15 correct and 30 new words (maximum $=15$ ). "Learning ability" was defined as the sum of correctly recalled words during the five immediate learning trials (maximum score $=75$ words). Raw scores were standardized into $z$-scores by substracting the group's mean from the individual score, followed by division by the group's SD. Further testing included tasks on executive functions and attention (Lezak, 2004).

MRI acquisition and analyses. MRI was performed on a Siemens Trio system operating at 3 tesla using a 12-channel head coil. Subjects underwent a 3D structural scanning protocol using high-resolution T1weighted magnetization prepared rapid gradient echo (MPRAGE) imaging $(\mathrm{TR}=1900 \mathrm{~ms}, \mathrm{TE}=2.52 \mathrm{~ms}, 192$ sagittal slices, voxel size $=$ $1.0 \times 1.0 \times 1.0 \mathrm{~mm}^{3}$, flip angle $\left.=9^{\circ}\right)$, and a diffusion-weighted spinecho echo-planar imaging (EPI) sequence $(\mathrm{TR}=7500 \mathrm{~ms}, \mathrm{TE}=86 \mathrm{~ms}$, 61 axial slices, voxel size $=2.3 \times 2.3 \times 2.3 \mathrm{~mm}^{3}$; 64 directions with a b-value of $1000 \mathrm{~s} / \mathrm{mm}^{2}$ and one b0). Functional scans were obtained at rest using a T2*-weighted EPI sequence $(\mathrm{TR}=2300 \mathrm{~ms}, \mathrm{TE}=30 \mathrm{~ms}, 34$ slices, voxel size $=3.0 \times 3.0 \times 4.0 \mathrm{~mm}^{3}$, flip angle $=90^{\circ}$ ). Subjects were instructed to keep their eyes closed and not to think of anything in particular during this 6 min scan. MRI analyses were done using the software packages FSL (www.fmrib.ox.ac.uk/fsl), AFNI (http://afni.nimh. nih.gov/afni), and freesurfer (http://surfer.nmr.mgh.harvard.edu/).

According to the functional anatomy and potential lateralization effects of the hippocampus (Burgess et al., 2002; Poppenk and Moscovitch, 
Table 1. Baseline characteristics dependent on group

\begin{tabular}{|c|c|c|c|}
\hline & Resveratrol & Placebo & $p$ \\
\hline$n$ (female/male) & $23(9 / 14)$ & $23(9 / 14)$ & \\
\hline Age (y) & $64.8 \pm 6.8(51-75)$ & $63.7 \pm 5.3(50-72)$ & $0.95^{b}$ \\
\hline Education (y) & $17.5 \pm 3.6(10-24)$ & $16.8 \pm 2.7(11-22)$ & $0.38^{b}$ \\
\hline Mini mental state examination (score) & $28.7 \pm 1.3(26-30)$ & $29.3 \pm 0.8(27-30)$ & $0.06^{c}$ \\
\hline Right-handedness (\%) ${ }^{a}$ & $71.1 \pm 36(-60,50-100)$ & $81.7 \pm 17(50-100)$ & $0.73^{c}$ \\
\hline Beck's Depression Index (score) & $3.9 \pm 3.2(0-11)$ & $7.3 \pm 5.0(1-18)$ & $0.02^{c}$ \\
\hline TMT, part A (time to complete, in sec) & $33.8 \pm 14.8(21-88)$ & $35.8 \pm 10.9(20-63)$ & $0.34^{c}$ \\
\hline TMT, part B (time to complete, in sec) & $79.5 \pm 41.9(33-220)$ & $88.1 \pm 51.1(43-300)$ & $0.52^{c}$ \\
\hline $\begin{array}{l}\text { Stroop color-word test (delay of incongruent } \\
\text { vs neutral condition, in sec) }{ }^{d}\end{array}$ & $41.2 \pm 13.0(0-11)$ & $45.0 \pm 11.3(0-11)$ & $0.35^{b}$ \\
\hline Verbal fluency, phonematic (no. of words) & $15.3 \pm 5.4(6-26)$ & $16.8 \pm 5.3(10-30)$ & $0.53^{c}$ \\
\hline Verbal fluency, categories (no. of words) & $14.4 \pm 4.1(6-23)$ & $13.5 \pm 3.8(6-22)$ & $0.47^{b}$ \\
\hline
\end{tabular}

Significant differences are indicated by bolding the number. Data are given as mean \pm SD and range (min-max). TMT, Trail-making test.

${ }^{a}$ Two subjects were excluded due to missing values.

${ }^{b}$ Paired $t$ test.

Wilcoxon signed-rank test.

${ }^{d}$ One subject was excluded due to color blindness.

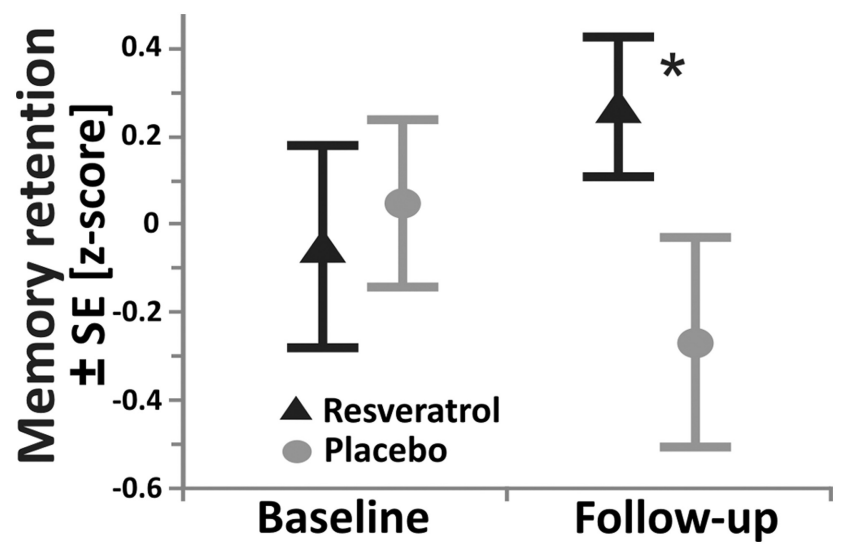

Figure 2. Memory retention performance dependent on group. Note the significant increase in performance after 26 weeks of resveratrol (triangles, black, $n=23$ ) compared with placebo (circles, gray, $n=23 ; p=0.038$ ). Memory retention was defined as the number of correct words immediately recalled after the fifth learning trial of the auditory verbal learning task subtracted from those correctly recalled after the 30 min delay. Raw scores were standardized into $z$-scores and multiplied by -1 to create positive relations. Triangles/circles indicate mean retention $z$-scores dependent on group and time point; error bars indicate SE. ${ }^{*} p<0.05$ according to paired $t$ test of differences between baseline and follow-up in memory scores between the resveratrol and placebo group-matched pairs.

2011), we conducted separate analyses for the anterior and posterior parts of the left and right hemisphere. For volumetry, the left and right hippocampus was delineated using FMRIB's Integrated Registration and Segmentation Tool (FIRST; Patenaude et al., 2011) on individual structural images. To determine the respective anterior and posterior parts, the center of gravities were assessed after rigid body transformation to MNI space and the corresponding $y$-coordinate then served as a measure for individual anterior/posterior-division as described previously (Erickson et al., 2011). Subsequently, nonbrain tissue was deleted using brain extraction tools and the brains were segmented using FMRIB's Automated Segmentation Tool (FAST) into gray matter, white matter, and CSF.

Microstructure of the hippocampus was assessed by mean diffusivity (MD) estimated using diffusion tensor imaging (DTI) as described previously (Kerti et al., 2013). A tensor model was fitted to the motioncorrected DTI data to create individual 3D images of MD. Then, individual T1-weighted images were coregistered to the b0 DTI images using rigid body transformations. These registrations were used to transform masks of the left and right hippocampus (derived on the T1 images) to the MD maps for extraction of the mean individual hippocampal MD value.
To assess potential changes in FC of the hippocampus, we used a customized longitudinal processing stream based on the 1000 Functional Connectomes Project (www.nitrc.org/projects/fcon_1000; Biswal et al., 2010). FC of the hippocampus was assessed using coregistered masks of the left and right anterior and posterior part of the hippocampus as seeds, similar to previous studies (Rombouts et al., 2005; Andrews-Hanna et al., 2010; Wang et al., 2010). Preprocessing of individual functional scans comprised slice time correction, motion correction, spatial smoothing with a $6 \mathrm{~mm}$ full-width-half-maximum Gaussian kernel, temporal filtering $(0.01-0.1 \mathrm{~Hz})$, and detrending. The functional scans were normalized to the anatomical image using affine coregistrations. Noise due to motion, white matter, CSF, and global change was removed from the functional signal by multiple regressions, creating standardized residual BOLD signal times series. Then, mean time series of the individual hippocampus seeds were correlated with times series of all other gray matter voxels using a general linear model (GLM) approach within FSL (FLAME). The resulting Pearson's $r$ correlation coefficient 3D maps were then Fisher's $z$-transformed to obtain a normal distribution. Registration of individual $z$-maps for group analysis included a rigid body withinsubject registration between time points to a "halfway space" before affine and nonlinear registrations to a study-specific template.

Blood parameters, anthropometric data, and vascular markers. Fasting blood donations were collected to assess levels of insulin, glucose, glycated hemoglobin Alc (HbAlc; two subjects had to be excluded due to methodological problems, i.e., coagulated blood sample, $n=1$; lost sample, $n=1$ ), total cholesterol, high- to low-density lipoprotein (HDL to LDL) ratio, triacylglycerides, leptin, brain-derived neurotrophic factor (BDNF), insulin-like growth factor 1 (IGF-1), tumor necrosis factor- $\alpha$ (TNF- $\alpha$ ), interleukin 6, and high-sensitive C-reactive protein (hs-CRP). All parameters were analyzed by trained personnel at the IMD laboratory, Berlin, Germany, according to standardized procedures. Anthropometry included body fat measured using bioelectrical impedance analysis, weight, and height. In addition, systolic and diastolic blood pressure was measured (one subject had to be excluded due to missing values). CIMT was assessed using B-mode duplex ultrasound of the distal right and left common carotid artery. Recordings were obtained according to the Mannheim Intima Media Thickness Consensus (Touboul et al., 2007). Subjects were resting in a supine position with the head turned to the contralateral side of the respective artery. CIMT of the far vessel wall was semiautomatically measured with the ultrasound transducer at 1 $\mathrm{cm}$ proximal to the carotid bulb using a commercially available standardized real-time measurement method (Mylab25Gold; Esaote). Four subjects had to be excluded due to missing values. CIMT was defined as the distance between the characteristic echoes of the lumen-intima interface and the media-adventitia interface. Mean values (measured in micrometers) were created by performing three CIMT measurements of each side. Mood during neuropsychological testing was assessed by the posi- 
Table 2. Memory performance according to the auditory verbal learning task dependent on group

\begin{tabular}{|c|c|c|c|c|c|c|}
\hline \multirow[b]{2}{*}{ Parameter (no. of words) } & \multicolumn{3}{|l|}{ Resveratrol } & \multicolumn{3}{|l|}{ Placebo } \\
\hline & Pre & Post & $p$ & Pre & Post & $p$ \\
\hline Retention & $-2.2 \pm 2.4$ & $-1.3 \pm 1.6$ & $0.041^{a}$ & $-2.0 \pm 2.0$ & $-2.4 \pm 2.4$ & $0.30^{b}$ \\
\hline Delayed recall & $10.6 \pm 4.0$ & $12.4 \pm 3.3$ & $\mathbf{0 . 0 1 1 ^ { a }}$ & $10.1 \pm 3.1$ & $10.7 \pm 3.3$ & $0.24^{b}$ \\
\hline Recognition & $12.0 \pm 3.3$ & $13.6 \pm 1.6$ & $0.015^{a}$ & $11.9 \pm 3.1$ & $13.1 \pm 2.3$ & $0.06^{a}$ \\
\hline Learning ability & $54.4 \pm 11.6$ & $59.7 \pm 9.3$ & $0.002^{b}$ & $51.6 \pm 9.6$ & $56.1 \pm 9$ & $0.006^{b}$ \\
\hline Fifth learning trial & $12.8 \pm 2.1$ & $13.6 \pm 1.9$ & $0.041^{a}$ & $12.0 \pm 1.7$ & $13.1 \pm 1.5$ & $0.011^{b}$ \\
\hline
\end{tabular}

Significant changes are indicated by bolding the number. Data are given as mean \pm SD (raw scores). Memory "retention" was defined as the number of correct words recalled after the fifth trial (maximum 15 words) subtracted from those correctly recalled after the 30 min delay (maximum 15 words) multiplied by 1 to create positive relations. "Delayed recall" was defined as the number of correctly recalled words after the 30 min delay (maximum 15 words) and "recognition" was defined as the number of correctly recognized words minus false positives out of a subsequent list of 45 words read out loudly that comprised 15 correct and 30 new words (maximum $=15$ ). "Learning ability" was defined as the sum of correctly recalled words during the five immediate learning trials (maximum score $=75$ words). Raw scores were standardized into $z$-scores by substracting the group's mean from the individual score, followed by division by the group's SD.

${ }^{a}$ Wilcoxon signed-rank test.

${ }^{b}$ Paired $t$ test.

Table 3. Total gray matter volume and hippocampal volume and microstructure of subjects before and after the intervention/control period

\begin{tabular}{|c|c|c|c|c|c|c|}
\hline \multirow[b]{2}{*}{ Parameter } & \multicolumn{3}{|l|}{ Resveratrol } & \multicolumn{3}{|l|}{ Placebo } \\
\hline & Pre & Post & $p^{a}$ & Pre & Post & $p^{a}$ \\
\hline $\begin{array}{l}\text { Total gray matter volume }\left(\mathrm{cm}^{3}\right) \\
\mathrm{HC}_{\text {ant }} \text {, left }\end{array}$ & $576.2 \pm 52.8$ & $575.3 \pm 54.7$ & 0.64 & $568.6 \pm 45.2$ & $566.7 \pm 43.0$ & 0.23 \\
\hline Volume $\left(\mathrm{cm}^{3}\right)$ & $2.28 \pm 0.35$ & $2.26 \pm 0.34$ & 0.57 & $2.21 \pm 0.28$ & $2.21 \pm 0.26$ & 0.87 \\
\hline $\mathrm{MD}\left(\mathrm{m}^{2} / \mathrm{s}\right)$ & $1.17 \pm 0.08$ & $1.18 \pm 0.07$ & 0.50 & $1.15 \pm 0.06$ & $1.16 \pm 0.08$ & 0.30 \\
\hline $\mathrm{HC}_{\text {post }}$, left & & & & & & \\
\hline Volume $\left(\mathrm{cm}^{3}\right)$ & $1.59 \pm 0.25$ & $1.58 \pm 0.24$ & 0.74 & $1.54 \pm 0.21$ & $1.56 \pm 0.20$ & 0.24 \\
\hline $\mathrm{MD}\left(\mathrm{m}^{2} / \mathrm{s}\right)$ & $1.08 \pm 0.10$ & $1.09 \pm 0.09$ & 0.71 & $1.09 \pm 0.09$ & $1.09 \pm 0.11$ & $0.50^{b}$ \\
\hline $\mathrm{HC}_{\mathrm{ant}}$, right & & & & & & \\
\hline Volume $\left(\mathrm{cm}^{3}\right)$ & $2.32 \pm 0.26$ & $2.29 \pm 0.29$ & 0.25 & $2.29 \pm 0.19$ & $2.33 \pm 0.19$ & 0.32 \\
\hline $\mathrm{MD}\left(\mathrm{m}^{2} / \mathrm{s}\right)$ & $1.11 \pm 0.07$ & $1.12 \pm 0.07$ & 0.43 & $1.13 \pm 0.08$ & $1.11 \pm 0.09$ & 0.41 \\
\hline $\mathrm{HC}_{\text {post }}$, right & & & & & & \\
\hline Volume $\left(\mathrm{cm}^{3}\right)$ & $1.65 \pm 0.21$ & $1.63 \pm 0.20$ & 0.08 & $1.63 \pm 0.17$ & $1.63 \pm 0.23$ & 0.96 \\
\hline $\mathrm{MD}\left(\mathrm{m}^{2} / \mathrm{s}\right)$ & $1.05 \pm 0.10$ & $1.07 \pm 0.08$ & 0.58 & $1.05 \pm 0.08$ & $1.06 \pm 0.11$ & 0.62 \\
\hline
\end{tabular}

Data are given as mean \pm SD. Microstructure was measured using MD estimates.

${ }^{a}$ Paired $t$ test except ${ }^{b}$ Wilcoxon-signed-rank-test.

tive and negative affect schedule (PANAS; one subject had to be excluded due to missing values; Krohne et al., 1996). Subjects also reported their physical activity and other lifestyle habits using the Freiburger physical activity questionnaire (Frey et al., 1999) implemented in a questionnaire on lifestyle habits (Flöel et al., 2008).

Statistical analysis. To detect significant effects of supplementary resveratrol on memory functions, we calculated paired $t$ tests of changes in AVLT outcome measures (baseline vs follow-up) between resveratrol subjects and their pairwise-matched controls. Additional paired $t$ tests or Wilcoxon signed-rank tests within each group were calculated to assess significant changes between time points, as appropriate. Changes over time in gray matter volume, hippocampal volume and microstructure, serum parameters, anthropometric measures, and vascular markers were evaluated at the between- and within-group level using paired $t$ tests or nonparametric tests, as appropriate. FC group analyses included gray matter-voxelwise GLM statistics implemented in FSL between changes in hippocampal FC in the resveratrol group compared with those in the control group. Gaussian random field theory was used to correct for multiple comparisons at the cluster level (clusterwise correction, $z>2.3$, $p<0.05$ ). Associations among changes in memory, hippocampal FC, and serum parameters were assessed using Pearson's or Spearman's correlations, as appropriate. Baseline group characteristics were compared using paired $t$ tests or Wilcoxon signed-rank tests. Normal distributions were tested by the Kolmogorov-Smirnov test. Levels of significance were set at $p<0.05$. Analyses were done using SPSS version 20 software (IBM) unless indicated otherwise.

\section{Results}

Baseline characteristics

Age, BMI, years of education, and MMSE score did not differ between the resveratrol and the placebo group (for details, see Table 1). Participants from the resveratrol group scored lower on the BDI compared with participants from the placebo group $(p=$ $0.02)$.

\section{Cognitive changes}

We observed a significant increase in retention of words over a 30 min delay after resveratrol compared with placebo (paired $t$ test of the differences, $t_{(22)}=2.2, p=0.038$; Fig. 2, Table 2). Adjusting for baseline differences in BDI and MMSE scores did not attenuate the effect (ANCOVA, retention, all $F_{(1,42)}>4.7$, all $p<$ 0.036). Further AVLT scores (delayed recall and recognition) supported the beneficial effect of resveratrol on memory functions on the within-group level (pre vs post, all $p<0.05$; Table 2), but failed to reach significance at the between-group level.

\section{Changes in volume, microstructure, and FC of the hippocampus}

No significant changes in total gray matter volume or in the volume or microstructure of the hippocampus were noted (all $p>$ 0.05; Table 3).

Subjects of the resveratrol group showed significant increases in FC of the hippocampus to frontal, parietal, and occipital areas compared with placebo (cluster-based thresholding, $p<0.05$; Fig. 3, Table 4); that is, between the left anterior hippocampus $\left(\mathrm{HC}_{\mathrm{ant}}\right)$ and the anterior cingulate cortex and precuneus (Fig. $3 B)$, between the left posterior hippocampus $\left(\mathrm{HC}_{\text {post }}\right)$ and the medial prefrontal cortex, precuneus, and left lateral angular cortex (Fig. $3 C$ ), and between the right $\mathrm{HC}_{\text {post }}$ and the right lateral occipital cortex (Fig. 3D). Notably, median increases in FC in the medial prefrontal cortex correlated significantly with increases in retention scores in the resveratrol group $(r=0.43, p=0.041$; Fig. 4). 


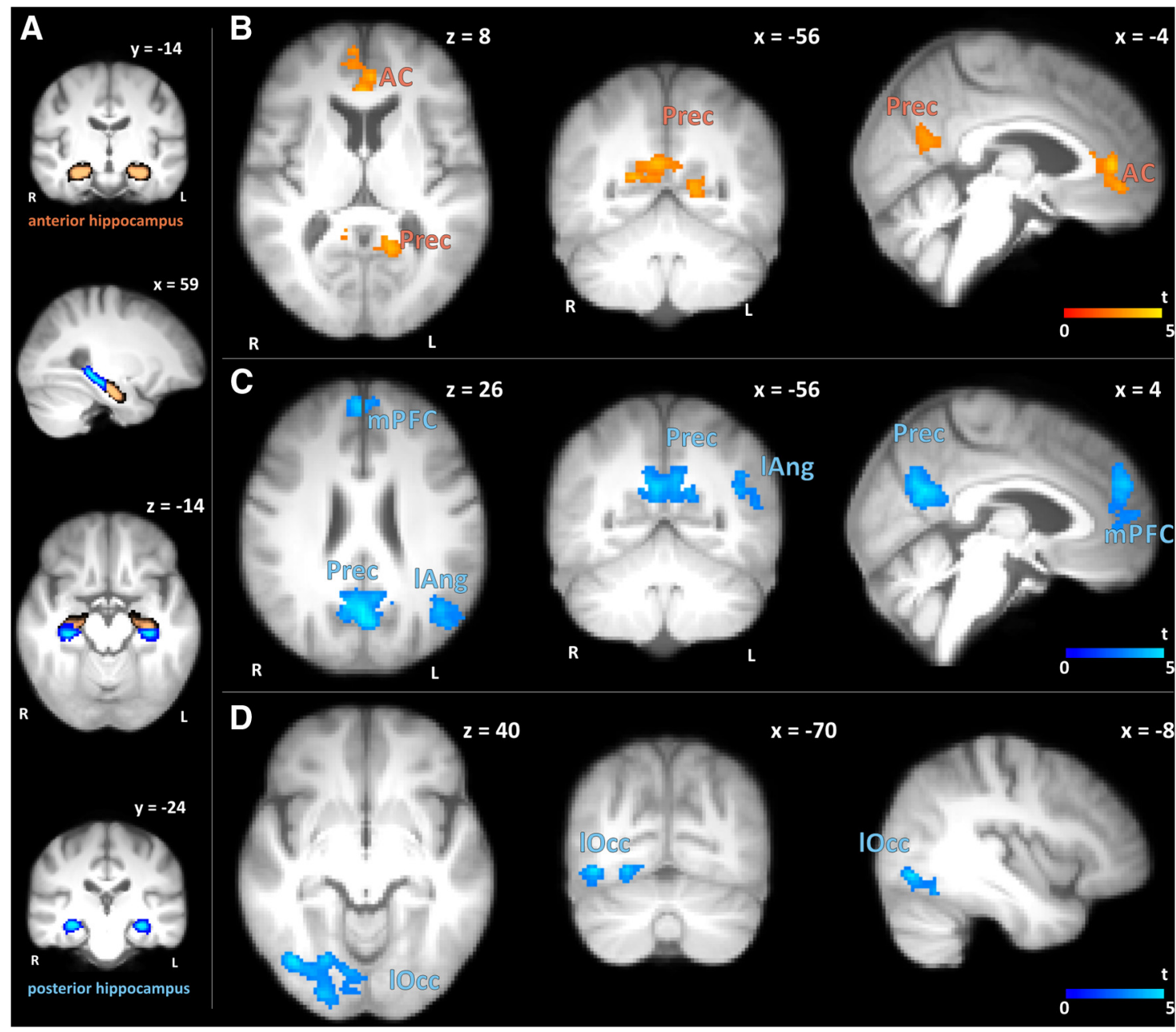

Figure 3. Increases in resting-state $\mathrm{FC}$ of the $\mathrm{HC}_{\text {ant }}$ and $\mathrm{HC}_{\text {post }}$ after 26 weeks of supplementary resveratrol $(n=23)$ versus placebo $(n=23)$. $\mathrm{FC}$ was measured using individual masks of the left and right anterior (orange) and posterior part (blue) of the hippocampus as seeds. $A$, Probabilities of included voxels in any of the subjects' $\mathrm{HC}_{\text {ant }}$ and $\mathrm{HC}_{\text {post }}$ masks coregistered to a study-specific

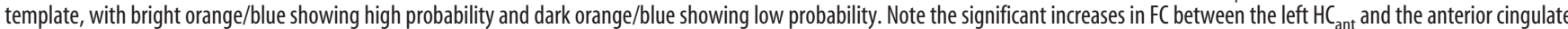
cortex (AC) and precuneus (Prec) shown in B. C, Significant increases in $\mathrm{FC}$ between the left $\mathrm{HC}_{\text {post }}$ and the medial prefrontal cortex (mPFC), left lateral angular cortex (IAng), and precunues (Prec). Selective increases in $\mathrm{FC}$ between the right $\mathrm{HC}_{\text {post }}$ and the right lateral occitipital cortex (IOcc) are visualized in $\boldsymbol{D}$. $\boldsymbol{B}$ - $\boldsymbol{D}$, Colors indicate $t$-values of significant voxels (cluster-based thresholding, $p<$ 0.05) superimposed on a study-specific template. Images are displayed in neurological convention, coordinates in mm according to MNI space. R, Right; L, left.

Table 4. Increases in resting-state $\mathrm{FC}$ of the $\mathrm{HC}_{\text {ant }}$ and $\mathrm{HC}_{\text {post }}$ after 26 weeks of supplementary resveratrol versus placebo (cluster-based thresholding, $p<0.05$ )

\begin{tabular}{|c|c|c|c|c|c|c|}
\hline \multirow[b]{2}{*}{ Seed } & \multirow[b]{2}{*}{ Brain area of increased FC } & \multirow[b]{2}{*}{$p$} & \multirow[b]{2}{*}{ No. of voxels } & \multicolumn{3}{|c|}{ MNI coordinates (hot voxel) } \\
\hline & & & & $x$ & $y$ & $z$ \\
\hline \multirow{2}{*}{$\overline{H C} C_{\text {ant }}$, left } & Anterior cingulate cortex & 0.006 & 516 & 12 & 46 & 4 \\
\hline & Precuneus & $<0.001$ & 672 & 18 & -54 & 12 \\
\hline \multirow{3}{*}{$H C_{\text {post }}$, left } & Medial prefrontal cortex & 0.036 & 435 & 4 & 52 & 28 \\
\hline & Precuneus & $<0.001$ & 1167 & -4 & -70 & 28 \\
\hline & Angular cortex, left & 0.005 & 613 & -7 & 26 & 1 \\
\hline $\mathrm{HC}_{\text {post }}$, right & Lateral occipital cortex, right & $<0.001$ & 928 & 40 & -70 & -8 \\
\hline
\end{tabular}

Changes in fasting serum levels

Subjects of the resveratrol group showed a significant reduction in HbAlc compared with placebo (paired $t$ test, $t_{(20)}=2.7, p=$ 0.014; Fig. 5A). In addition, leptin concentrations significantly increased in the resveratrol group compared with decreases in the placebo group (Wilcoxon-signed-rank test, $z=3.6, p<0.001$; Fig. 5B).

Decreases in HbAlc correlated with median increases in FC in the medial prefrontal cortex $(r=-0.67, p<0.001$; Fig. $5 C)$ and with increases in memory retention of words over a $30 \mathrm{~min}$ delay (n.s., $r=-0.3, p=0.19)$ and leptin $(r=-0.5, p=0.013)$ in the resveratrol group.

No selective changes were noted between groups for changes in glucose and insulin, lipid profile, inflammatory markers, BDNF, or IGF-1 (all $p<0.05$ ). For details of serum parameters, see Table 5.

\section{Changes in anthropometric data and vascular markers}

The resveratrol group showed a significant reduction in body fat of $1.2 \pm 3 \%$ SD compared with increases $(0.9 \pm 3 \% \mathrm{SD})$ after 


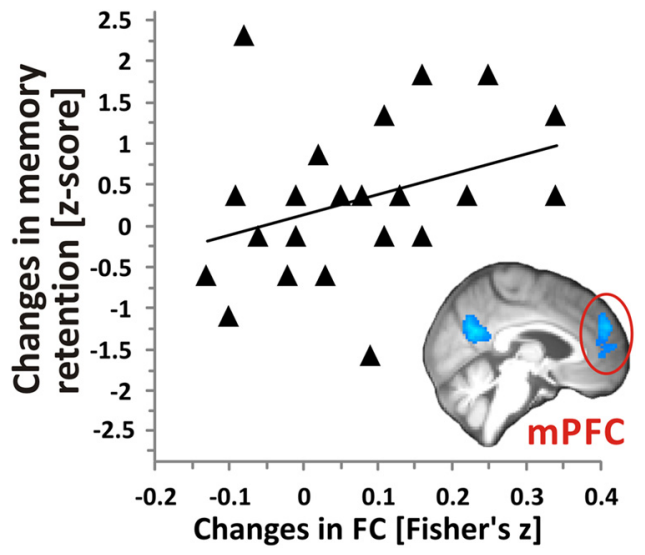

Figure 4. Intervention-induced changes in FC correlate with changes in retention of words over a 30 min delay in subjects of the resveratrol group $(n=23)$. Memory retention was defined as the number of correct words immediately recalled after the fifth learning trial of the auditory verbal learning task subtracted from those correctly recalled after the 30 min delay. Raw scores were standardized into $z$-scores and multiplied by -1 to create positive relations. Triangles show median changes in FC within a significant cluster in the left medial prefrontal cortex (mPFC, outlined in red, see inset; for details, see Fig. 3) using the left posterior hippocampus as seed in relation to changes in retention scores. Spearman's correlation, $r=0.4, p=0.04$, line gives regression fit.

placebo (paired $t$ test, $t_{(21)}=2.3, p=0.033$ ). No significant differences were found between groups for body weight, BMI, blood pressure, and CIMT (all $p>0.05$ ). However, in the resveratrol group, subjects exhibited reductions in body weight and BMI (n.s., all $p<0.16$ ) and decreases in systolic (n.s., $p=0.17$ ) and diastolic blood pressure $(p=0.036)$. Self-reported physical activity and mood did not change significantly. For details, see Table 5.

\section{Discussion}

This interventional study showed for the first time that supplementary resveratrol over a period of 26 weeks improved retention of words over a 30 min delay and FC of the hippocampus with frontal, parietal, and occipital areas in healthy older overweight adults compared with placebo. In addition, resveratrol led to a significant decrease in peripheral HbAlc, a long-term marker of glucose control. Increases in retention scores and decreases in HbAlc correlated with selective increases in FC of the left posterior hippocampus with medial prefrontal areas. We also observed a significant reduction of body fat and increases in leptin compared with placebo.

\section{Cognitive changes}

Our findings of improved memory performance due to resveratrol intake support the hypothesis based on in vitro and in vivo studies that resveratrol exerts positive effects on brain function (for review, see Baur and Sinclair, 2006). For example, cognitive benefits were reported after 8 weeks of introgastric resveratrol application in a mouse model of accelerated senescence (Liu et al., 2012). Memory improvements were also found after resveratrol or red wine consumption in several rodent models of $\mathrm{AD}$ (Sharma and Gupta, 2002; Wang et al., 2006; Kim et al., 2007). Moreover, gray mouse lemurs performed significantly better in a spatial memory task after resveratrol compared with placebo (Dal-Pan et al., 2011). However, human studies addressing potential cognitive effects of supplementary resveratrol over several days or weeks are lacking. In a small study, Kennedy et al. (2010) found an increase in cerebral blood flow in healthy younger adults immediately after a single dose of 250 and $500 \mathrm{mg}$ of resveratrol. Although the investigators could not observe enhanced cognitive (memory) scores directly after resveratrol intake, beneficial effects on brain perfusion noted in that study may translate into behavioral improvements after a sufficiently longer duration of resveratrol intake. Note that our study had a duration of 6 months with $200 \mathrm{mg}$ per day, similar to a number of ongoing studies addressing cognitive effects of resveratrol in healthy older subjects and in $\mathrm{AD}$ patients that have not yet been completed (see www.clinicaltrials.gov website).

\section{Changes in resting-state $\mathrm{FC}$}

Selective increases in resting-state FC patterns of the hippocampus observed in our participants after resveratrol may reflect improvements in the integrity and functionality of the hippocampus. In the last decade, the concept of resting-state FC has been increasingly propagated as a new dynamic and predictive biomarker for the early detection of brain changes in the course of normal aging and AD (Greicius et al., 2004; Sorg et al., 2007; Biswal et al., 2010; Prvulovic et al., 2011; Chhatwal and Sperling, 2012). For example, altered resting state FC within several largescale brain networks, including the "default mode" network comprising the hippocampus (Buckner et al., 2008), has been frequently linked with memory formation decline and neurodegeneration (Greicius et al., 2004; Buckner et al., 2005; Rombouts et al., 2005; Andrews-Hanna et al., 2007). In addition, previous studies in healthy subjects reported correlations between memory performance and increased FC; for example, between the bilateral hippocampus (Wang et al., 2010) and between the medial PFC and left inferior parietal cortex (He et al., 2012). Moreover, changes in resting-state FC have been postulated as promising candidate surrogate markers for interventional trials indicating or predicting clinically relevant effects (Prvulovic et al., 2011; Chhatwal and Sperling, 2012); however, longitudinal studies that successfully implemented resting state FC are scarce. Therefore, our findings that intervention-induced increases in left $\mathrm{HC}_{\text {post }}{ }^{-}$ $\mathrm{mPFC}$ correlated with improvements in memory scores may not only support the crucial role of this functional connection for memory performance, but also demonstrate for the first time that long-term supplementation of a CR mimetic leads to a detectable increase in hippocampal FC. This may have further implications for the use of resting-state networks or even as a quantitative biomarker in interventional trials.

\section{Underlying mechanisms}

We observed significant resveratrol-induced reductions in the long-term marker of glucose control, HbAlc, consistent with previous preclinical studies (Mizutani et al., 2000; Baur et al., 2006; Lagouge et al., 2006) and results from interventional human trials (Brasnyó et al., 2011; Timmers et al., 2011; Crandall et al., 2012). Therefore, resveratrol may induce improvements in energy metabolism, similar to what has been observed in CR and consistent with the proposed role of resveratrol as a CR mimetic, which may account for at least some of the beneficial effects of resveratrol on neuronal function (Baur and Sinclair, 2006; Ingram et al., 2006; Stranahan and Mattson, 2008). This hypothesis is further supported by the strong correlation of reductions in HbAlc with increases in hippocampal FC and trendwise with memory performance in the resveratrol subjects. The hippocampus and related cognitive processes are thought to be particularly vulnerable to disturbances in glucose supply and metabolism (McNay et al., 2000). Moreover, the negative effects of higher glucose include reduced cerebral blood flow, disturbances of in- 
A

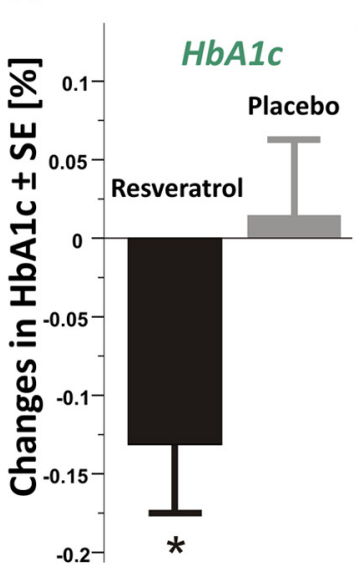

B

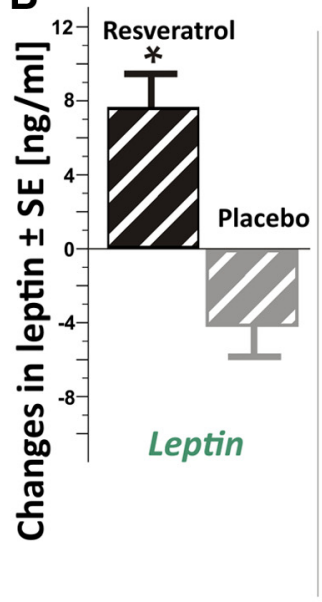

C

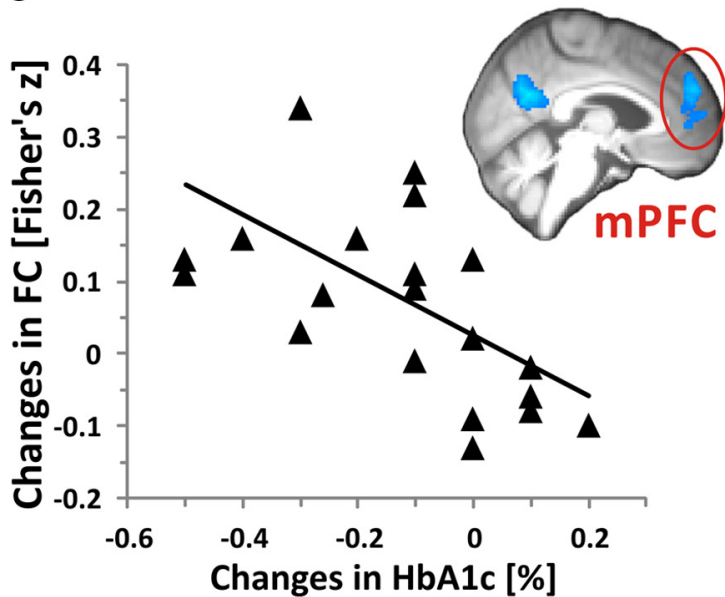

Figure 5. Changes in glycated HbA1c and leptin. $\boldsymbol{A}$, Note the significant decrease in fasting HbA1c after resveratrol (black bar, $n=21$ ) compared with placebo (gray bar, $n=21 ; p=0.014)$. $\boldsymbol{B}$, Leptin concentrations significantly increased after resveratrol (black striped bar, $n=23$ ) and decreased after placebo (gray striped bar; $n=23$ ). $C$, In the resveratrol group, decreases in $\mathrm{HbA1C}$ correlated significantly with increases in $\mathrm{FC}(n=21 ; r=0.4, p=0.04)$. Triangles show median changes in FC within a significant cluster in the left medial prefrontal cortex (outlined in red, see inset; for details, see Fig. 3) using the left posterior hippocampus as seed in relation to changes in HbA1c. Line indicates regression fit. ${ }^{*} p<0.05$, paired $t$ test.

Table 5. Fasting serum parameters, anthropometric measures, vascular parameters, physical activity, and mood of subjects before and after the intervention/control period

\begin{tabular}{|c|c|c|c|c|c|c|}
\hline \multirow[b]{2}{*}{ Parameter } & \multicolumn{3}{|l|}{ Resveratrol } & \multicolumn{3}{|l|}{ Placebo } \\
\hline & Pre & Post & $p$ & Pre & Post & $p$ \\
\hline $\mathrm{HbA1c}, \%^{a}$ & $5.83 \pm 0.2$ & $5.70 \pm 0.2$ & $0.007^{e}$ & $5.85 \pm 0.3$ & $5.88 \pm 0.3$ & $0.53^{e}$ \\
\hline Insulin (mU) & $7.8 \pm 3.4$ & $9.8 \pm 6.3$ & $0.046^{f}$ & $9.2 \pm 4.5$ & $8.5 \pm 3.4$ & $0.47^{f}$ \\
\hline Total cholesterol (mg/dl) & $221.5 \pm 33.1$ & $231.4 \pm 36.8$ & $0.008^{e}$ & $223.4 \pm 33.4$ & $220.6 \pm 36.4$ & $0.53^{e}$ \\
\hline LDL-to-HDL ratio & $2.5 \pm 1.1$ & $2.7 \pm 1.5$ & $0.06^{e}$ & $2.5 \pm 0.6$ & $2.5 \pm 0.7$ & $0.76^{e}$ \\
\hline Triacylglycerides (mg/dl) & $103.8 \pm 42.4$ & $115 \pm 53.5$ & $0.18^{e}$ & $115.7 \pm 44.7$ & $110.0 \pm 50.5$ & $0.47^{e}$ \\
\hline IGF-1 (ng/ml) & $132.5 \pm 34$ & $134.4 \pm 38$ & $0.63^{e}$ & $140.3 \pm 45$ & $136.0 \pm 36$ & $0.52^{e}$ \\
\hline TNF-alpha (pg/ml) & $10.3 \pm 2.3$ & $8.0 \pm 1.8$ & $<0.001^{e}$ & $15.7 \pm 15.3$ & $9.5 \pm 2.1$ & $0.006^{f}$ \\
\hline Interleukin 6 (pg/ml) & $2.9 \pm 1.2$ & $2.0 \pm 0.2$ & $0.002^{f}$ & $7.9 \pm 19.8$ & $4.0 \pm 8.9$ & $\mathbf{0 . 0 2 1 ^ { f }}$ \\
\hline hsCRP (pg/ml) & $1.3 \pm 1.3$ & $1.5 \pm 1.4$ & $0.18^{f}$ & $2.7 \pm 3.2$ & $6.2 \pm 19.3$ & $0.86^{f}$ \\
\hline Body fat $(\%)^{a}$ & $30 \pm 7.6$ & $28.8 \pm 7.6$ & $0.082^{e}$ & $30.0 \pm 8.0$ & $30.9 \pm 7.2$ & $0.20^{f}$ \\
\hline Weight, kg & $81.8 \pm 9.8$ & $81.3 \pm 10$ & $0.16^{e}$ & $83 \pm 7.7$ & $83 \pm 7.6$ & $0.98^{e}$ \\
\hline Diastolic blood pressure $(\mathrm{mm} \mathrm{Hg})^{d}$ & $92.7 \pm 9$ & $87.5 \pm 11$ & $0.036^{e}$ & $88.0 \pm 11$ & $86.6 \pm 12$ & $0.60^{e}$ \\
\hline Physical activity (kcal/week ${ }^{2}$ ) & $5646 \pm 2829$ & $5797 \pm 1089$ & $0.86^{e}$ & $4946 \pm 3850$ & $5086 \pm 4670$ & $0.52^{f}$ \\
\hline Positive PANAS score ${ }^{d}$ & $34.1 \pm 6.0$ & $32.0 \pm 5.7$ & $0.13^{e}$ & $32.2 \pm 6.5$ & $31.4 \pm 7.2$ & $0.29^{e}$ \\
\hline Negative PANAS score ${ }^{d}$ & $10.8 \pm 1.5$ & $11.2 \pm 1.7$ & $0.50^{f}$ & $12.4 \pm 3.2$ & $11.8 \pm 2.2$ & $0.18^{f}$ \\
\hline
\end{tabular}

Significant changes are indicated by bolding the number. Data are given as mean \pm SD.

${ }^{a}$ Two subjects.

${ }^{b}$ Three subjects.

Four subjects.

${ }^{d}$ One subject excluded due to missing values.

${ }^{e}$ Paired $t$ test.

'Wilcoxon signed-rank test.

tracellular second messenger pathways, and imbalance in the generation and scavenging of reactive oxygen species or advanced glycation of important proteins in the brain (Brownlee, 2001). In older humans, we and others recently observed that chronically elevated glucose levels even within the normal range correlate with lower memory performance and decreased hippocampal volume and microstructure (Cherbuin et al., 2012; Kerti et al., 2013). Therefore, based on the above-described mechanisms, an improved glucose metabolism after resveratrol might have ex- erted protective effects on neuronal functioning within the hippocampus and subsequent increased synchronization patterns of related FC networks, which were detectable using resting-state fMRI. We also observed selective decreases in body fat and increases in leptin after resveratrol and preclinical evidence suggests that leptin exerts neuroprotective and neurotrophic effects (for review, see Paz-Filho et al., 2010). However, because the groups already differed in leptin levels at baseline, selective increases in leptin after resveratol versus placebo are difficult to 
interpret and the role of leptin in resveratrol-induced cognitive benefits remains to be explored in future studies. Other positive effects of resveratrol may include improvements of vascular factors, including lowered blood pressure (Miatello et al., 2005; Do et al., 2008; Silan, 2008). Although nonsignificant at the group level, we observed decreases in diastolic blood pressure in the resveratrol group, which provides support for vascular impact. Conversely, subjects of the resveratrol group displayed increased total cholesterol at the within-group level, which contradicts previous trials (Timmers et al., 2011). Future studies are needed to clarify this issue, for example, by implementing a more detailed assessment of lipid metabolism with additional measures of nonesterified fatty acids or apolipoporoteins. In addition, this study reported that resveratrol improved inflammation (Timmers et al., 2011); however, we could not observe selective effects of resveratrol on inflammatory markers because both groups displayed lower values at follow-up. Future interventional studies with a higher sample size and/or implementing serum assays with higher sensitivity to low-grade inflammation are needed to clarify these issues.

\section{Limitations}

Several limitations should be considered when interpreting our findings. First, we did not measure resveratrol or its metabolites, so compliance to regular capsule intake relied on self-reported information and counts of remaining capsules. However, note that no established long-term marker of resveratrol intake is available to date and group-specific decreases in HbAlc after resveratrol clearly indicate that subjects adhered to the intervention (Timmers et al., 2011). Second, the placebo group scored significantly higher on BDI scores at baseline and depression can potentially bias memory performance. However, memory scores at baseline did not significantly differ between groups and adjustment of differences in BDI scores did not attenuate the observed effects of resveratrol, rendering a potential confounding of differences in BDI scores in our sample unlikely. Third, we did not conduct muscle biopsies to assay gene or protein expression profiles. Therefore, potential effects on, for example, the sirtuin pathways (Baur and Sinclair, 2006) have to be fully elucidated in future trials. Fourth, a still relatively short intervention time might have prevented us from observing significant differences in vascular markers and hippocampal volume and microstructure. As a strength, our subjects comprised well characterized, healthy individuals free of signs for beginning cognitive impairment, brain pathologies, or severe diseases and within a small BMI range $\left(25-30 \mathrm{~kg} / \mathrm{m}^{2}\right)$ and who were pairwise matched for sex, age, and BMI.

\section{Conclusion and outlook}

In this double-blind placebo-controlled interventional study, we found evidence that 26 weeks of supplementary resveratrol improved memory performance and FC of the hippocampus in healthy overweight older adults. We also demonstrated improved glucose metabolism as a potential underlying mechanism, which even in the normal range could exert harmful effects when chronically elevated (Kerti et al., 2013). Therefore, our findings further support the hypothesis that resveratrol acts as an easy caloric restriction mimetic, inducing similar positive effects on glucose metabolism and subsequent neuronal function and cognitive performance. Moreover, neuroimaging results indicated selective changes in resting-state FC networks of the hippocampus after resveratrol that were linked with behavioral improvements. This finding further supports the use of resting-state fMRI as a promising dynamic biomarker for upcoming clinical trials. In sum, the present results may pave the way to implement larger randomized clinical trials for the use of caloric restriction mimetics as one potential strategy to maintain brain health until old age.

\section{References}

Andrews-Hanna JR, Snyder AZ, Vincent JL, Lustig C, Head D, Raichle ME, Buckner RL (2007) Disruption of large-scale brain systems in advanced aging. Neuron 56:924-935. CrossRef Medline

Andrews-Hanna JR, Reidler JS, Sepulcre J, Poulin R, Buckner RL (2010) Functional-anatomic fractionation of the brain's default network. Neuron 65:550-562. CrossRef Medline

Baur JA, Pearson KJ, Price NL, Jamieson HA, Lerin C, Kalra A, Prabhu VV, Allard JS, Lopez-Lluch G, Lewis K, Pistell PJ, Poosala S, Becker KG, Boss O, Gwinn D, Wang M, Ramaswamy S, Fishbein KW, Spencer RG, Lakatta EG, et al. (2006) Resveratrol improves health and survival of mice on a high-calorie diet. Nature 444:337-342. CrossRef Medline

Baur JA, Sinclair DA (2006) Therapeutic potential of resveratrol: the in vivo evidence. Nat Rev Drug Discov 5:493-506. CrossRef Medline

Biswal BB, Mennes M, Zuo XN, Gohel S, Kelly C, Smith SM, Beckmann CF, Adelstein JS, Buckner RL, Colcombe S, Dogonowski AM, Ernst M, Fair D, Hampson M, Hoptman MJ, Hyde JS, Kiviniemi VJ, Kötter R, Li SJ, Lin CP, et al. (2010) Toward discovery science of human brain function. Proc Natl Acad Sci U S A 107:4734-4739. CrossRef Medline

Brasnyó P, Molnár GA, Mohás M, Markó L, Laczy B, Cseh J, Mikolás E, Szijártó IA, Mérei A, Halmai R, Mészáros LG, Sümegi B, Wittmann I (2011) Resveratrol improves insulin sensitivity, reduces oxidative stress and activates the Akt pathway in type 2 diabetic patients. Br J Nutr 106: 383-389. CrossRef Medline

Brownlee M (2001) Biochemistry and molecular cell biology of diabetic complications. Nature 414:813-820. CrossRef Medline

Buckner RL, Snyder AZ, Shannon BJ, LaRossa G, Sachs R, Fotenos AF, Sheline YI, Klunk WE, Mathis CA, Morris JC, Mintun MA (2005) Molecular, structural, and functional characterization of Alzheimer's disease: evidence for a relationship between default activity, amyloid, and memory. J Neurosci 25:7709-7717. CrossRef Medline

Buckner RL, Andrews-Hanna JR, Schacter DL (2008) The brain's default network: anatomy, function, and relevance to disease. Ann N Y Acad Sci 1124:1-38. CrossRef Medline

Burgess N, Maguire EA, O’Keefe J (2002) The human hippocampus and spatial and episodic memory. Neuron 35:625-641. CrossRef Medline

Cherbuin N, Sachdev P, Anstey KJ (2012) Higher normal fasting plasma glucose is associated with hippocampal atrophy: the PATH Study. Neurology 79:1019-1026. CrossRef Medline

Chhatwal JP, Sperling RA (2012) Functional MRI of mnemonic networks across the spectrum of normal aging, mild cognitive impairment, and Alzheimer's disease. J Alzheimers Dis 31:S155-S167. Medline

Crandall JP, Oram V, Trandafirescu G, Reid M, Kishore P, Hawkins M, Cohen HW, Barzilai N (2012) Pilot study of resveratrol in older adults with impaired glucose tolerance. J Gerontol A Biol Sci Med Sci 67:1307-1312. CrossRef Medline

Csiszar A, Labinskyy N, Olson S, Pinto JT, Gupte S, Wu JM, Hu F, Ballabh P, Podlutsky A, Losonczy G, de Cabo R, Mathew R, Wolin MS, Ungvari Z (2009) Resveratrol prevents monocrotaline-induced pulmonary hypertension in rats. Hypertension 54:668-675. CrossRef Medline

Dal-Pan A, Pifferi F, Marchal J, Picq JL, Aujard F; RESTRIKAL Consortium (2011) Cognitive performances are selectively enhanced during chronic caloric restriction or resveratrol supplementation in a primate. PLoS One 6:e16581. CrossRef Medline

De Santi C, Pietrabissa A, Spisni R, Mosca F, Pacifici GM (2000) Sulphation of resveratrol, a natural compound present in wine, and its inhibition by natural flavonoids. Xenobiotica 30:857-866. CrossRef Medline

Do GM, Kwon EY, Kim HJ, Jeon SM, Ha TY, Park T, Choi MS (2008) Long-term effects of resveratrol supplementation on suppression of atherogenic lesion formation and cholesterol synthesis in apo E-deficient mice. Biochem Biophys Res Commun 374:55-59. CrossRef Medline

Erickson KI, Voss MW, Prakash RS, Basak C, Szabo A, Chaddock L, Kim JS, Heo S, Alves H, White SM, Wojcicki TR, Mailey E, Vieira VJ, Martin SA, Pence BD, Woods JA, McAuley E, Kramer AF (2011) Exercise training increases size of hippocampus and improves memory. Proc Natl Acad Sci U S A 108:3017-3022. CrossRef Medline

Flöel A, Witte AV, Lohmann H, Wersching H, Ringelstein EB, Berger K, 
Knecht S (2008) Lifestyle and memory in the elderly. Neuroepidemiology 31:39-47. CrossRef Medline

Folstein MF, Folstein SE, McHugh PR (1975) "Mini-mental state": a practical method for grading the cognitive state of patients for the clinician. J Psychiatr Res 12:189-198. CrossRef Medline

Frey I, Berg A, Grathwohl D, Keul J (1999) [Freiburg Questionnaire of physical activity-development, evaluation and application]. Soz Praventivmed 44:55-64. CrossRef Medline

Ghanim H, Sia CL, Abuaysheh S, Korzeniewski K, Patnaik P, Marumganti A, Chaudhuri A, Dandona P (2010) An antiinflammatory and reactive oxygen species suppressive effects of an extract of Polygonum cuspidatum containing resveratrol. J Clin Endocrinol Metab 95:E1-E8. CrossRef Medline

Greicius MD, Srivastava G, Reiss AL, Menon V (2004) Default-mode network activity distinguishes Alzheimer's disease from healthy aging: evidence from functional MRI. Proc Natl Acad Sci U S A 101:4637-4642. CrossRef Medline

He J, Carmichael O, Fletcher E, Singh B, Iosif AM, Martinez O, Reed B, Yonelinas A, Decarli C (2012) Influence of functional connectivity and structural MRI measures on episodic memory. Neurobiol Aging 33:26122620. CrossRef Medline

Ingram DK, Zhu M, Mamczarz J, Zou S, Lane MA, Roth GS, deCabo R (2006) Calorie restriction mimetics: an emerging research field. Aging Cell 5:97-108. CrossRef Medline

Ingram DK, Young J, Mattison JA (2007) Calorie restriction in nonhuman primates: assessing effects on brain and behavioral aging. Neuroscience 145:1359-1364. CrossRef Medline

Kamogawa K, Kohara K, Tabara Y, Uetani E, Nagai T, Yamamoto M, Igase M, Miki T (2010) Abdominal fat, adipose-derived hormones and mild cognitive impairment: the J-SHIPP study. Dement Geriatr Cogn Disord 30: 432-439. CrossRef Medline

Kennedy DO, Wightman EL, Reay JL, Lietz G, Okello EJ, Wilde A, Haskell CF (2010) Effects of resveratrol on cerebral blood flow variables and cognitive performance in humans: a double-blind, placebo-controlled, crossover investigation. Am J Clin Nutr 91:1590-1597. CrossRef Medline

Kerti L, Witte AV, Winkler A, Grittner U, Rujescu D, Flöel A (2013) Higher glucose levels associated with lower memory and reduced hippocampal microstructure. Neurology 81:1746-1752. CrossRef Medline

Kim D, Nguyen MD, Dobbin MM, Fischer A, Sananbenesi F, Rodgers JT, Delalle I, Baur JA, Sui G, Armour SM, Puigserver P, Sinclair DA, Tsai LH (2007) SIRT1 deacetylase protects against neurodegeneration in models for Alzheimer's disease and amyotrophic lateral sclerosis. EMBO J 26: 3169-3179. CrossRef Medline

Krohne H, Egloff B, Kohlmann C, Tausch A (1996) Untersuchungen mit einer deutschen Version der "Positive and Negative Affective Schedule" (PANAS). Diagnostica 42:139-156.

Kuhner C, Burger C, Keller F, Hautzinger M (2007) Reliability and validity of the Revised Beck Depression Inventory (BDI-II). Results from German samples [article in German]. Nervenarzt 78:651-656.

Lagouge M, Argmann C, Gerhart-Hines Z, Meziane H, Lerin C, Daussin F, Messadeq N, Milne J, Lambert P, Elliott P, Geny B, Laakso M, Puigserver P, Auwerx J (2006) Resveratrol improves mitochondrial function and protects against metabolic disease by activating SIRT1 and PGC-1alpha. Cell 127:1109-1122. CrossRef Medline

Lezak MD (2004) Neuropsychological assessment, Ed 4. New York, Oxford: OUP.

Lieb W, Beiser AS, Vasan RS, Tan ZS, Au R, Harris TB, Roubenoff R, Auerbach S, DeCarli C, Wolf PA, Seshadri S (2009) Association of plasma leptin levels with incident Alzheimer disease and MRI measures of brain aging. JAMA 302:2565-2572. CrossRef Medline

Liu GS, Zhang ZS, Yang B, He W (2012) Resveratrol attenuates oxidative damage and ameliorates cognitive impairment in the brain of senescenceaccelerated mice. Life Sci 91:872-877. CrossRef Medline

McNay EC, Fries TM, Gold PE (2000) Decreases in rat extracellular hippocampal glucose concentration associated with cognitive demand during a spatial task. Proc Natl Acad Sci U S A 97:2881-2885. CrossRef Medline

Miatello R, Vázquez M, Renna N, Cruzado M, Zumino AP, Risler N (2005) Chronic administration of resveratrol prevents biochemical cardiovascu- lar changes in fructose-fed rats. Am J Hypertens 18:864-870. CrossRef Medline

Mizutani K, Ikeda K, Nishikata T, Yamori Y (2000) Phytoestrogens attenuate oxidative DNA damage in vascular smooth muscle cells from strokeprone spontaneously hypertensive rats. J Hypertens 18:1833-1840. CrossRef Medline

Must A, Spadano J, Coakley EH, Field AE, Colditz G, Dietz WH (1999) The disease burden associated with overweight and obesity. JAMA 282:15231529. CrossRef Medline

Patenaude B, Smith SM, Kennedy DN, Jenkinson M (2011) A Bayesian model of shape and appearance for subcortical brain segmentation. Neuroimage 56:907-922. CrossRef Medline

Paz-Filho G, Wong ML, Licinio J (2010) The procognitive effects of leptin in the brain and their clinical implications. Int J Clin Pract 64:1808-1812. CrossRef Medline

Poppenk J, Moscovitch M (2011) A hippocampal marker of recollection memory ability among healthy young adults: contributions of posterior and anterior segments. Neuron 72:931-937. CrossRef Medline

Prvulovic D, Bokde AL, Faltraco F, Hampel H (2011) Functional magnetic resonance imaging as a dynamic candidate biomarker for Alzheimer's disease. Prog Neurobiol 95:557-569. CrossRef Medline

Rombouts SA, Barkhof F, Goekoop R, Stam CJ, Scheltens P (2005) Altered resting state networks in mild cognitive impairment and mild Alzheimer's disease: an fMRI study. Hum Brain Mapp 26:231-239. CrossRef Medline

Sharma M, Gupta YK (2002) Chronic treatment with trans resveratrol prevents intracerebroventricular streptozotocin induced cognitive impairment and oxidative stress in rats. Life Sci 71:2489-2498. CrossRef Medline

Silan C (2008) The effects of chronic resveratrol treatment on vascular responsiveness of streptozotocin-induced diabetic rats. Biol Pharm Bull 31:897-902. CrossRef Medline

Sorg C, Riedl V, Mühlau M, Calhoun VD, Eichele T, Läer L, Drzezga A, Förstl H, Kurz A, Zimmer C, Wohlschläger AM (2007) Selective changes of resting-state networks in individuals at risk for Alzheimer's disease. Proc Natl Acad Sci U S A 104:18760-18765. CrossRef Medline

Stranahan AM, Mattson MP (2008) Impact of energy intake and expenditure on neuronal plasticity. Neuromolecular Med 10:209-218. CrossRef Medline

Sun AY, Wang Q, Simonyi A, Sun GY (2011) Botanical phenolics and neurodegeneration. In: Herbal medicine: biomolecular and clinical aspects, Ed 2 (Benzie IFF, Wachtel-Galor S, eds). Boca Raton, FL: CRC.

Timmers S, Konings E, Bilet L, Houtkooper RH, van de Weijer T, Goossens GH, Hoeks J, van der Krieken S, Ryu D, Kersten S, Moonen-Kornips E, Hesselink MK, Kunz I, Schrauwen-Hinderling VB, Blaak EE, Auwerx J, Schrauwen P (2011) Calorie restriction-like effects of 30 days of resveratrol supplementation on energy metabolism and metabolic profile in obese humans. Cell Metab 14:612-622. CrossRef Medline

Touboul PJ, Hennerici MG, Meairs S, Adams H, Amarenco P, Bornstein N, Csiba L, Desvarieux M, Ebrahim S, Fatar M, Hernandez Hernandez R, Jaff M, Kownator S, Prati P, Rundek T, Sitzer M, Schminke U, Tardif JC, Taylor A, Vicaut E, et al. (2007) Mannheim carotid intima-media thickness consensus (2004-2006). An update on behalf of the Advisory Board of the 3rd and 4th Watching the Risk Symposium, 13th and 15th European Stroke Conferences, Mannheim, Germany, 2004, and Brussels, Belgium, 2006. Cerebrovasc Dis 23:75-80. CrossRef Medline

Wang J, Ho L, Zhao Z, Seror I, Humala N, Dickstein DL, Thiyagarajan M, Percival SS, Talcott ST, Pasinetti GM (2006) Moderate consumption of Cabernet Sauvignon attenuates Abeta neuropathology in a mouse model of Alzheimer's disease. FASEB J 20:2313-2320. CrossRef Medline

Wang L, Negreira A, LaViolette P, Bakkour A, Sperling RA, Dickerson BC (2010) Intrinsic interhemispheric hippocampal functional connectivity predicts individual differences in memory performance ability. Hippocampus 20:345-351. CrossRef Medline

Wild S, Roglic G, Green A, Sicree R, King H (2004) Global prevalence of diabetes: estimates for the year 2000 and projections for 2030. Diabetes Care 27:1047-1053. CrossRef Medline

Wong RH, Howe PR, Buckley JD, Coates AM, Kunz I, Berry NM (2011) Acute resveratrol supplementation improves flow-mediated dilatation in overweight/obese individuals with mildly elevated blood pressure. Nutr Metab Cardiovasc Dis 21:851-856. CrossRef Medline 